\title{
Beneficial 'unintended effects' of a cereal cystatin in transgenic lines of potato, Solanum tuberosum
}

Aurélie Munger ${ }^{1}$, Karine Coenen ${ }^{1}$, Line Cantin ${ }^{1}$, Charles Goulet ${ }^{1,2}$, Louis-Philippe Vaillancourt ${ }^{1}$, Marie-Claire Goulet ${ }^{1}$, Russell Tweddell ${ }^{1}$, Frank Sainsbury ${ }^{1}$ and Dominique Michaud ${ }^{1 *}$

\begin{abstract}
Background: Studies reported unintended pleiotropic effects for a number of pesticidal proteins ectopically expressed in transgenic crops, but the nature and significance of such effects in planta remain poorly understood. Here we assessed the effects of corn cystatin II (CCII), a potent inhibitor of C1A cysteine (Cys) proteases considered for insect and pathogen control, on the leaf proteome and pathogen resistance status of potato lines constitutively expressing this protein.
\end{abstract}

Results: The leaf proteome of lines accumulating CCII at different levels was resolved by 2-dimensional gel electrophoresis and compared with the leaf proteome of a control (parental) line. Out of ca. 700 proteins monitored on 2-D gels, 23 were significantly up- or downregulated in CCIl-expressing leaves, including 14 proteins detected de novo or up-regulated by more than five-fold compared to the control. Most up-regulated proteins were abiotic or biotic stress-responsive proteins, including different secretory peroxidases, wound inducible protease inhibitors and pathogenesis-related proteins. Accordingly, infection of leaf tissues by the fungal necrotroph Botryris cinerea was prevented in CCIl-expressing plants, despite a null impact of CCII on growth of this pathogen and the absence of extracellular Cys protease targets for the inhibitor.

Conclusions: These data point to the onset of pleiotropic effects altering the leaf proteome in transgenic plants expressing recombinant protease inhibitors. They also show the potential of these proteins as ectopic modulators of stress responses in planta, useful to engineer biotic or abiotic stress tolerance in crop plants of economic significance.

Keywords: Transgenic crops, Transgene pleiotropy, Unintended effects, Stress/defense-related proteome, Corn cystatin, Potato (Solanum tuberosum)

\section{Background}

Several studies have described the potential of recombinant protease inhibitors as potent antidigestive compounds to protect crop plants from herbivory or pathogenic infection [1,2]. For instance, cysteine (Cys) protease inhibitors of the cystatin protein superfamily were proposed as protective agents against various herbivorous arthropods and root-parasitic nematodes [3,4]. Cystatins and most other protease inhibitors in plants are competitive protein inhibitors acting as pseudosubstrates to enter the active site of proteases [5].

\footnotetext{
* Correspondence: dominique.michaud@fsaa.ulaval.ca

${ }^{1}$ Centre de recherche en horticulture, Département de phytologie, Université Laval, Pavillon des Services, 2440 boul. Hochelaga, Québec, QC, G1V OA6, Canada

Full list of author information is available at the end of the article
}

Following inhibition, the target proteases can no longer cleave peptide bonds, which results in a detrimental inhibition of protein digestive functions in herbivorous pests and accounts for the resistance of several transgenic plant lines expressing recombinant inhibitors.

The heterologous expression of protease inhibitors in plants, however, has raised a number of questions about the possible occurrence of unintended metabolic interference -or pleiotropic effects- on endogenous proteolysis, which could eventually alter important cellular functions [2]. Proteases are ubiquitous metabolic effectors involved in the regulation of numerous cellular processes, ranging from housekeeping functions like protein turnover and the elimination of misfolded polypeptides to the processing of polypeptide pre- and pro-regions on maturing protein backbones [6,7]. While studies have

\section{Biomed Central}


reported negligible phenotypic effects for protease inhibitors in transgenic plants based on the assessment of macroscopic indicators such as growth rate, stem diameter or leaf number [8-10], several reports suggest the onset of more subtle effects at the metabolic level. For instance, plant and mammalian serine (Ser) protease inhibitors ectopically expressed in potato were shown to significantly impact protein levels in leaves, positively or negatively $[10,11]$. Similarly, recombinant cystatins expressed in Arabidopsis or tobacco were shown to induce a range of phenotype alterations in planta, including a delayed development of floral organs [12], a modified physiological behaviour under low temperature or light regimes [13], an altered protein content in leaves $[13,14]$, and a strong repression of the pathogeninducible hypersensitive response [15].

These findings, along with studies reporting the tolerance of protease inhibitor-expressing plants to abiotic stress cues such as drought, salinity and low temperatures [13,16-18], point to the occurrence of endogenous protease targets for the recombinant inhibitors, directly or indirectly involved in stress-related processes. The socalled pleiotropic effects of recombinant protease inhibitors, which are often considered as unintended metabolic effects in the modified plant, might simply reflect a lack of knowledge on stress-related proteolysis in planta and in fact represent a source of potentially useful traits for crop improvement [2]. Here we provide experimental evidence for the up-regulation of abiotic and biotic stress-related proteins in leaves of transgenic potato lines engineered to express corn cystatin II (CCII), a potent inhibitor of $\mathrm{C} 1 \mathrm{~A}$ Cys proteases exhibiting potential for herbivore pest control $[19,20]$. We also link the pleiotropic effects of CCII expression with the compromised ability of a model necrotrophic fungus, Botrytis cinerea, to colonize leaf tissues of the modified host plant.

\section{Results and discussion}

\section{Pathogenesis-related proteins are up-regulated in} CCII-expressing potato lines

Reverse transcriptase (RT) PCR, immunodetection and surface-enhanced laser desorption ionization timeof-flight mass spectrometry (SELDI TOF MS) analyses were performed to select transgenic potato lines expressing CCII at different levels in leaves (Figure 1A,B), among a collection of independent transformants developed earlier in our laboratory [21]. CCII in these lines accumulates in the cytosolic compartment, under the control of the Cauliflower mosaic virus $35 \mathrm{~S}$ constitutive promoter. Unlike control line $\mathrm{K}$ showing no signal, the transgenic lines showed variable, but easily detectable signals of CCII-encoding mRNA transcripts (Figure 1A). Accordingly, CCII was immunodetected as a $\sim 12-\mathrm{kDa}$ polypeptide band of variable intensity in the modified lines, in contrast with line $\mathrm{K}$ giving no signal (Figure 1B). The amount of CCII in leaf extracts was variable among the lines, as inferred by SELDI TOF MS after capture of the inhibitor on CM-10 biochips for weak cationic exchange (Figure 1A). Unexpectedly, a clear immunoblot signal was detected in several CCII-lines for the wound inducible homologue of CCII in potato leaves, potato multicystatin (PMC) [22] (Figure 1B). This apparent upregulation of the endogenous inhibitor was confirmed by densitometric analysis of the immunoblots revealing significant increases reaching two- to tenfold the signals observed for control line $\mathrm{K}$ in four transgenic lines, out of five tested (Student's $t$-test; $P<0.05$ ) (Figure $1 C$ ).

RT PCR assays were conducted with nucleotide primers for mRNA transcripts of proteinase inhibitor II (Pin-II), a protein marker of wound and jasmonate inducible proteins; and pathogenesis-related (PR) protein $\mathrm{P} 4$, a protein marker of the abiotic stress-/pathogeninducible salicylic acid pathway [23] (Figure 2A). Transcript levels for Pin-II were not different in control and transgenic lines (Student's $t$-test; $P=0.10$ ), while transcripts for protein P4 were found at higher levels in several CCII-expressing lines, including line 9.4 and line 10.4 $(P<0.05)$. This observation suggesting an up-regulation of salicylate inducible proteins in the CCII-expressing lines was further supported by immunodetection assays with primary antibodies for PR-2 (ß-glucanase) and PR-3 (chitinase) proteins, which showed levels of proteins from both families to be significantly higher in lines 4.1c, 9.4 and 10.4 compared to control line $\mathrm{K}$ (Student's $t$-tests; $P<0.05$ ) (Figure 2B,C).

\section{The stress-related proteome is altered in CCII-expressing leaves}

A comparative two-dimensional gel electrophoresis (2-DE) proteome analysis was conducted with leaf protein extracts of line 9.4, line 10.4 and control line $\mathrm{K}$ to measure the overall impact of CCII on the host plant's leaf proteome, and to test the hypothesis of a specific up-regulation of salicylate inducible stress-related proteins in plants ectopically expressing the recombinant inhibitor (Figure 3; Table 1). Out of $\sim 700$ protein spots monitored on 2-D gels, 23 showed a significantly altered level in CCII-expressing lines compared to the control line, for similar amounts of protein loaded on gel strips (ANOVA; $P<0.05$ ) (Figure 3A). Of these proteins, 15 were detected de novo or up-regulated by more than fivefold in the CCII-lines (Table 1). As observed above for PR proteins (Figure 2), the up-regulating effects of CCII were systematically stronger in line 10.4 compared to line 9.4 producing lower levels of CCII (Figure 3B), thereby suggesting a dose-dependent effect for the recombinant inhibitor.

Most proteins up-regulated in the CCII-lines were confidently identified based on LC-MS/MS sequence 

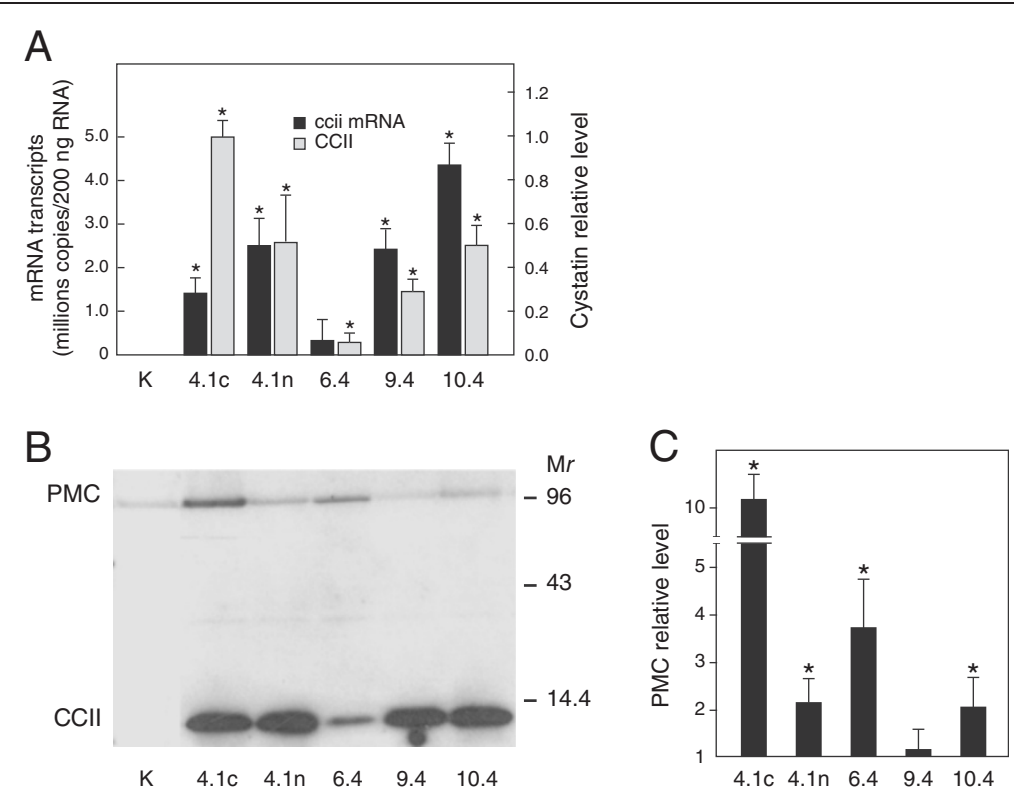

Figure 1 Expression of CCII and potato multicystatin in leaves of transgenic potato lines. A. CCII and ccii transcript levels in leaves of control line $\mathrm{K}$ and five independent transgenic lines, as determined by SELDI TOF MS and real-time RT PCR. mRNA transcripts were quantified based on a standard curve with incremental amounts of ccii transgene as a template. CCII levels are expressed as relative amounts compared to line 4.1c (mean value of 1.0). B. Immunodetection of CCII (11.7 kDa) with primary antibodies directed against oryzacystatin I, a structural homologue from rice [22]. Numbers on the right refer to commercial molecular weight markers. PMC refers to endogenous potato multicystatin. C. Relative PMC levels in CCII-lines compared to mean basal level in control line K (arbitrary value of 1). Each bar on panels A and C is the mean of three independent (plant replicate) values \pm SE. Asterisks indicate a significant difference with control line K (Student's t-test; $P<0.05$ ).

data (Table 1; Additional file 1). In accordance with the increased levels of PMC and PR proteins in transgenic leaves (see above), several up-regulated proteins in lines 9.4 and 10.4 corresponded to defense-related proteins usually induced upon wounding or biotic stress challenge, such as for instance wound inducible Ser protease inhibitors (Spots 9 and 11 on Figure 3A), a Kunitz cathepsin D inhibitor (Spot 21), a PR-2 (ß-glucanase) protein (Spot 18) and three PR-3 (chitinase) proteins or protein fragments (Spots 7, 10 and 16). Proteins that are usually induced upon abiotic stress challenge and thought to protect cells from oxidative damage or osmotic imbalance were also identified, including an osmotin-like PR-5 protein (Spot 19) and several secretory peroxidases (Spots 3, 14, 15 and 17). A number of studies in recent years have described the potential usefulness of ectopically expressing antioxidant enzymes -or positive regulators of these enzymes- to generate crop lines tolerant to adverse abiotic conditions such as low or high temperatures, drought or salinity [24-28]. Considering the above described pleiotropic effects of CCII on the potato leaf proteome, the reported ability of cystatinexpressing plants to cope more efficiently with abiotic stress conditions $[13,16]$ could be likely explained, at least in part, by a significant up-regulating effect of the recombinant inhibitors on the steady-state levels of these enzymes in leaf tissues.

\section{CCII does not inhibit the extracellular proteases of Botrytis cinerea}

Bioassays were conducted with the fungal necrotroph B. cinerea to document the possible positive impact of CCII pleiotropic effects, including PR protein up-regulation, on potato plants challenged with an aggressive microbial pathogen. The increased expression of peroxidases and PR proteins in leaves treated with benzathiadiazole, a functional analogue of salicylic acid, was shown earlier to induce resistance to B. cinerea in different plants (e.g. $[29,30]$ ). Likewise, strong detrimental effects against this pathogen were reported for recombinant PR proteins or gene inducers of these proteins expressed in different plants, including potato [31-34]. The documented repressing effect of recombinant cystatins on the pathogeninducible hypersensitive response in transgenic plants [15] could also impact the ability of $B$. cinerea to colonize CCII-leaf tissues. This pleiotropic effect of recombinant cystatins, also observed in plants treated with synthetic Cys protease inhibitors or transformed with DNA sequences to silence Cys proteases expression [35], would be correlated with an increase of cystatin:Cys protease ratios in planta preventing the release of free Cys proteases to initiate cell death [36]. This ectopic phenotype could represent, along with the constitutive overexpression of stress-related proteins, a major hurdle to the progression of the necrotroph, which relies on cell 
A

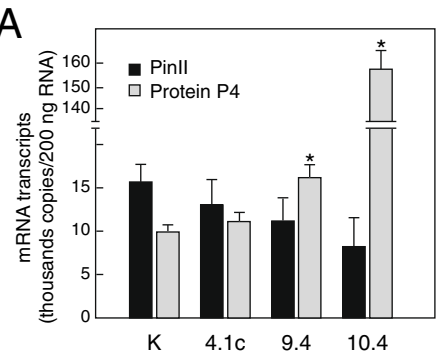

C

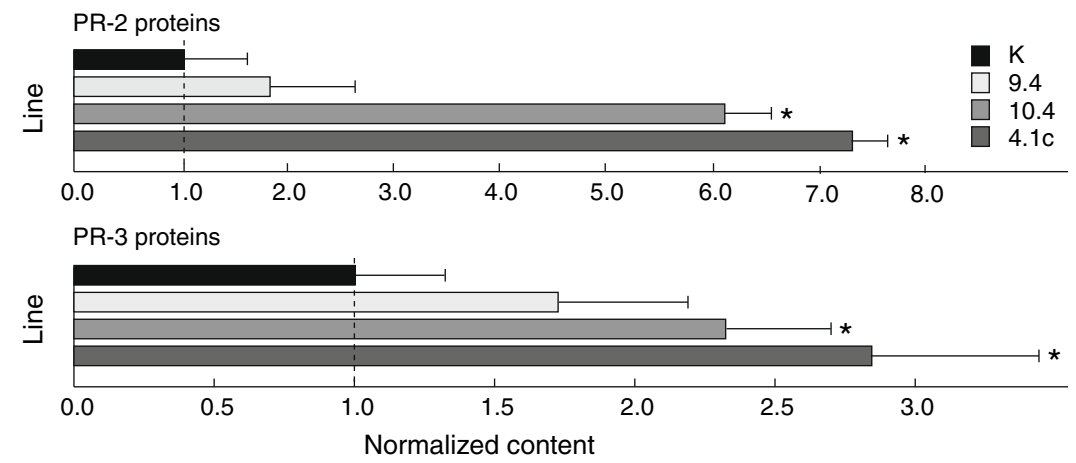

B
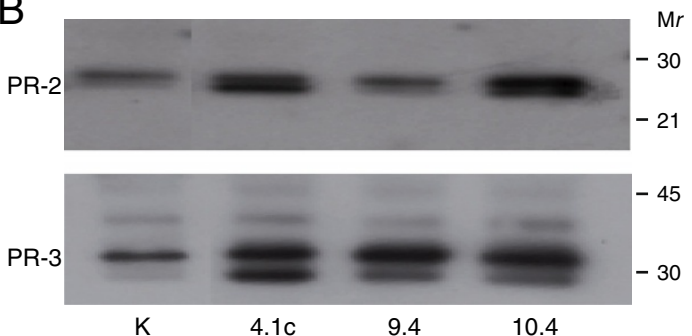

K 9.4 10.4

\section{.}

Figure 2 Expression of endogenous defense proteins in leaves of control line $\mathrm{K}$ and $\mathrm{CCI}$-expressing lines 4.1c, 9.4 and 10.4. A. mRNA transcripts for wound inducible proteinase inhibitor II (Pin-II) and pathogen inducible PR-1 protein P4, as determined by real-time RT PCR. Transcripts were assayed based on standard curves with incremental amounts of pin-II or protein p4 genes as templates. B. Immunodetection of PR-2 ( $\beta$-glucanase) and PR-3 (chitinase) proteins using commercial primary antibodies directed against tobacco structural homologues. Numbers on the right refer to commercial molecular weight markers. $\mathbf{C}$. Relative levels of PR-2 and PR-3 proteins in line K (relative value of 1.0) and CCll-lines, as estimated by quantitative densitometry after immunoblot digitalization. Each bar on panels $A$ and $C$ is the mean of three or four independent (plant replicate) values \pm SE. Asterisks indicate a significant difference with control line $\mathrm{K}(\mathrm{Student} s \mathrm{t}$-test; $P<0.05$ ).

death induction to generate dead tissues and successfully colonize the host plant [37-41].

Protease activity assays were first performed to measure the relative abundance of secreted Cys proteases in B. cinerea, and to evaluate the possibility of a direct, Cys protease inhibitory-mediated effect of CCII against this fungus. In agreement with earlier studies reporting the presence of aspartate (Asp) proteases in the secretome of B. cinerea $[42,43]$ and proposing a key role for these enzymes during plant infection [44-46], protease (azocaseinase) activities in the liquid phase of a $B$. cinerea culture grown in potato dextrose broth were inactivated by almost $50 \%$ with pepstatin A, a specific inhibitor of A1 Asp proteases (Table 2). Ser protease activities were also detected, as inferred by a weak, but reproducible inhibitory effect of Ser-type inhibitors on azocaseinase activity. The presence of (a) secreted Ser protease(s) in the culture medium was confirmed by the detection of a clear protein lysis band following gelatin/SDS-PAGE, strongly inhibited by the Ser-type inhibitor soybean trypsin inhibitor (Figure 4A, Rf mobility of 0.56 ). A second band was detected in gelatin-polyacrylamide gels, with an $\mathrm{R} f$ mobility of 0.70 . This protease, mostly active in acidic conditions (not shown) and insensitive to commonly used class-specific diagnostic inhibitors including pepstatin A
(Figure 4A, inset gel), likely corresponded to the pepstatin-insensitive G1 Asp protease BcACP1 identified as an additional determinant of pathogenic infection by B. cinerea [46]. Pepstatin-sensitive azocaseinases could not be visualized following gelatin/PAGE as reported earlier for other A1 Asp proteases [47], but could be enriched in mild conditions by affinity chromatography with pepstatin-agarose beads (Figure 4B). Unlike Asp and Ser protease inhibitors, Cys-type inhibitors, such as the fungal inhibitor trans-epoxysuccinyl-L-leucylamido(4-guanidino) butane (E-64) and different cystatins of plant or animal origin, did not inhibit azocaseinase or gelatinase activities (Table 2; Figure 4A). Overall, these observations pointed to the net predominance of Asp and Ser proteases in the culture medium of B. cinerea, as suggested by recent high-throughput proteomic studies on the secretome of this model organism [42,43]. They also suggested the absence of Cys protease targets for cystatins and the likely innocuity of CCII against the fungus.

\section{The pleiotropic effects of $\mathrm{CCI}$ induce resistance to Botrytis cinerea in potato}

Because studies have reported negative effects for plant cystatins against a number of pathogenic fungi including 


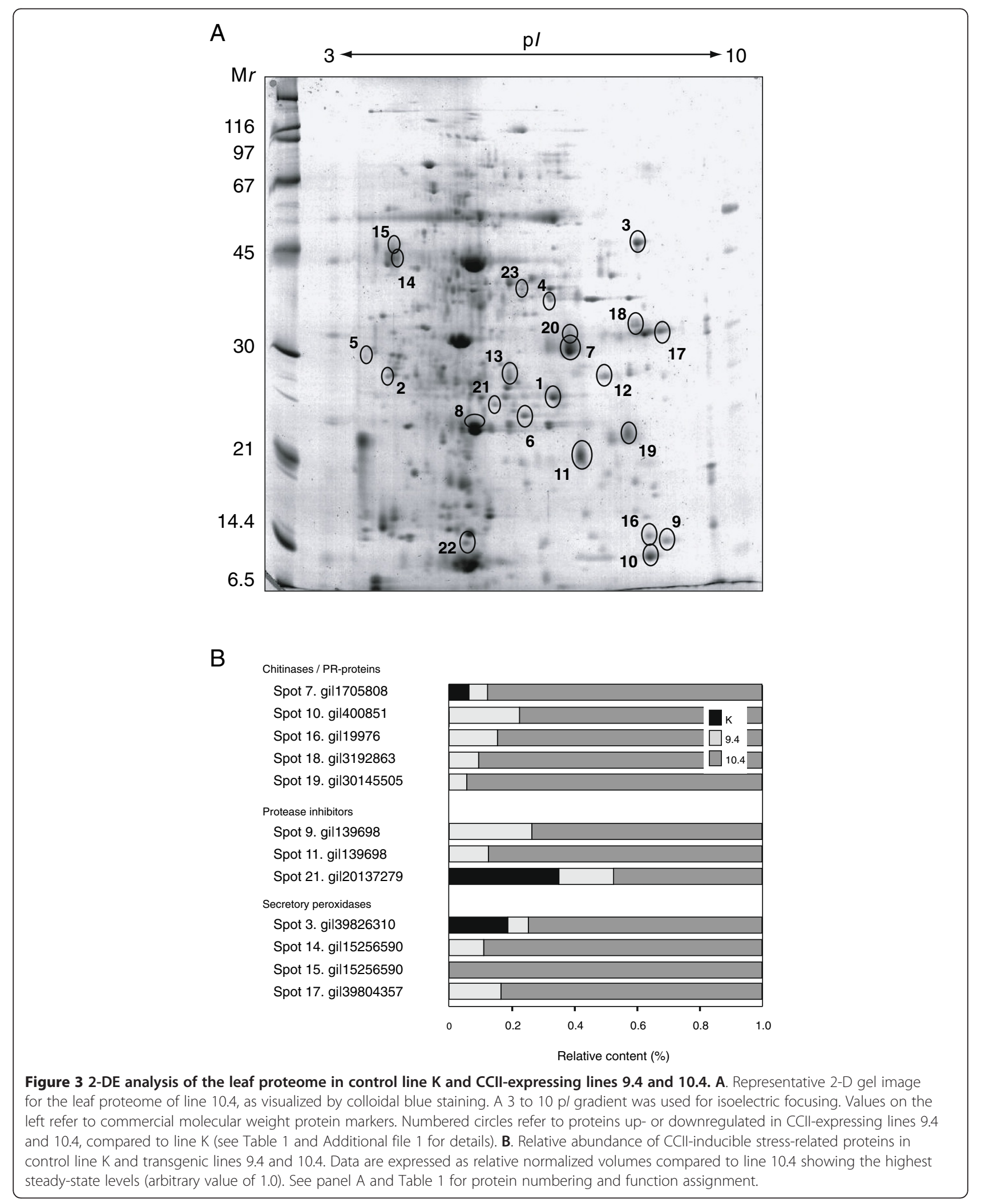


Table 1 Proteins up- or downregulated in CCII-expressing potato lines 9.4 and $10.4^{1}$

\begin{tabular}{|c|c|c|c|c|c|}
\hline \multirow[t]{2}{*}{ Spot \# } & \multirow[t]{2}{*}{ Protein identity ${ }^{2}$} & \multirow{2}{*}{$\begin{array}{l}\text { NCBI Accession } \\
\text { Number }^{3}\end{array}$} & \multicolumn{3}{|c|}{ Normalized volume $^{4}$} \\
\hline & & & Line $\mathrm{K}$ & Line 9.4 & Line 10.4 \\
\hline 1 & SOUL heme-binding protein & gi|53779330 & 0.41 & 0.40 & 0.63 \\
\hline 2 & EGD2 protein & gi|13615277 & 0.10 & 0.08 & 0.04 \\
\hline 3 & Secretory peroxidase & gi|39826310 & 0.06 & 0.08 & 0.30 \\
\hline 4 & Mitochondrial NAD-dependent malate dehydrogenase & gi|21388544 & 0.03 & 0.05 & 0.13 \\
\hline 6 & Multimeric flavodoxin WrbA & gi|537002029 & 0.02 & 0.06 & 0.18 \\
\hline 7 & Endochitinase 2 precursor & gi|1705808 & 0.12 & 0.24 & 1.93 \\
\hline 8 & $230 \mathrm{kDa}$ oxygen evolving protein of photosystem II & gi|11134035 & 2.90 & 2.13 & 1.58 \\
\hline 9 & WIN1 (wound-induced inhibitor 1) precursor & gi|139698 & & 0.02 & 0.09 \\
\hline 10 & Pathogenesis-related protein P2 precursor & gi|400851 & & 0.08 & 0.36 \\
\hline 11 & WIN1 (wound-induced inhibitor 1) precursor & gi|139698 & & 0.08 & 0.64 \\
\hline 13 & Short-chain dehydrogenase & gi|77403673 & & 0.03 & 0.22 \\
\hline 14 & Secretory peroxidase & gi|15256590 & & 0.02 & 0.21 \\
\hline 15 & Secretory peroxidase & gi|15256590 & & & 0.10 \\
\hline 16 & Pathogenesis-related protein P2 & gi|19976 & & 0.02 & 0.10 \\
\hline 17 & Secretory peroxidase & gi|39804357 & & 0.06 & 0.34 \\
\hline 18 & 1,3ß-glucan glucanhydrolase & gi|3192863 & & 0.02 & 0.26 \\
\hline 19 & Osmotin 81 & gi|30145505 & & 0.03 & 0.53 \\
\hline 20 & Endochitinase 2 precursor & gi|1705808 & 0.10 & 0.10 & 0.01 \\
\hline 21 & Aspartic protease inhibitor 9 & gi|20137279 & 0.06 & 0.08 & 0.16 \\
\hline 22 & Pentapeptide repeat protein & gi|53782287 & 0.29 & 0.20 & 0.08 \\
\hline 23 & FBP aldolase la & gi|39816882 & 0.17 & 0.10 & 0.04 \\
\hline
\end{tabular}

${ }^{1}$ 2-DE spatial coordinates, MOWSE score, protein sequence coverage, number of matched peptides and matched peptide sequences are given for each protein in Additional file 1.

${ }^{2}$ Protein spots 5 and 12 could not be identified based on available MS spectra.

${ }^{3}$ All protein spots matched potato (Solanum tuberosum) protein sequences, except Spot 10 and Spot 16 matching tomato (Solanum lycopersicum) sequences.

${ }^{4}$ Blanks indicate no detectable protein product.

B. cinerea (e.g. [48-52]), in vitro bioassays were carried out with purified CCII to rule out a possible, although unexpected, protease inhibition-independent toxic effect against the model fungus. In contrast with studies reporting significant effects for barley and strawberry cystatins [51,52], CCII had no significant effect on fungal biomass production (Student's $t$-test; $P=0.18$ ) (Figure 5A). This observation, along with both the retention of CCII in the cytosol of potato leaf cells (see [21]) and the absence of Cys protease targets in the extracellular milieu (above), confirmed the relevance of $B$. cinerea as a pathogenic model to assess the impact of CCII-mediated, defense-related pleiotropic effects in the CCII-expressing lines, without the risk of confounding effects due to fungal protease inhibition.

In vivo bioassays were conducted with a conidial suspension of the pathogen to compare leaf infection dynamics and symptom development patterns on leaves of line 9.4, line 10.4 and control line $\mathrm{K}$ (Figure 5B,C). Visual symptoms were recorded over 12 days postinfection and categorized along a ' 0 to 5 ' scale, where 0 indicated no symptom and 5 visible mycelium growth at the leaf surface (see Methods). As expected, line K exhibited several symptoms, starting with chlorosis of mesophyll tissue after a few days, followed by tissue necrosis at the inoculation site, black areas at leaf extremities indicating vascular tissue infection, and silver spots on most leaves indicative of active mycelium growth. By comparison, no fungal mycelium could be observed on the CCII-expressing leaves, and necrosis symptoms were systematically less severe, especially for line 10.4 expressing larger amounts of CCII (Figure 5B). The incidence rate of visual symptoms after 12 days was significantly lower on transgenic leaves (ANOVA; $P<0.01$ ), as inferred from a relative cumulative symptom score of less than $10 \%$ for line 10.4 compared to control line $\mathrm{K}$ (Figure 5C). These observations pointed overall to a protective effect of CCII in potato plants interacting with $B$. cinerea, likely explained by the stress-related pleiotropic effects of this inhibitor in leaf tissues.

\section{Conclusion}

Studies have reported significant pleiotropic effects for recombinant cystatins expressed in transgenic plant lines, notably including stress tolerance phenotypes suggesting an impact on endogenous stress-related 
Table 2 Inhibitory effect of diagnostic protease inhibitors on Botrytis cinerea secreted proteases ${ }^{1}$

\begin{tabular}{|c|c|c|c|}
\hline Inhibitor $^{2}$ & $\begin{array}{l}\text { Target } \\
\text { proteases }\end{array}$ & $\begin{array}{l}\text { Working } \\
\text { concentration } \\
(\mu \mathrm{M})\end{array}$ & $\begin{array}{l}\text { Inhibitory } \\
\text { activity (\%) }\end{array}$ \\
\hline Pepstatin A & Asp & 30 & $46 \pm 3$ \\
\hline PMSF & Ser & 3,000 & $15 \pm 2$ \\
\hline AEBSF & Ser & 300 & $7 \pm 2$ \\
\hline Soybean trypsin inhibitor & Ser & 10 & $7 \pm 2$ \\
\hline Leupeptin & Cys/Ser & 300 & $2 \pm 2$ \\
\hline $\mathrm{E}-64$ & Cys & 100 & $3 \pm 1$ \\
\hline Chicken egg white cystatin & Cys & 25 & $3 \pm 4$ \\
\hline Oryzacystatin I & Cys & 25 & $3 \pm 3$ \\
\hline Oryzacystatin II & Cys & 25 & $2 \pm 3$ \\
\hline EDTA & Metallo- & 3,000 & $3 \pm 3$ \\
\hline
\end{tabular}

${ }^{1} \mathrm{An}$ azocaseinase assay was performed at $\mathrm{pH} 5.0$, for $3 \mathrm{~h}$ at $37^{\circ} \mathrm{C}$. Values are expressed as relative inhibitory activities compared to an uninhibited control $(0 \%$ inhibition). Each datum is the mean of three values \pm SE.

${ }^{2}$ AEBSF, 4-(2-aminoethyl)-benzenesulfonyl fluoride, hydrochloride; E-64, transepoxysuccinyl-L-leucylamido-(4-guanidino) butane; EDTA, ethylenediamine tetraacetic acid; PMSF, phenylmethylsulfonyl fluoride.

responses. In line with these findings, our data showing an up-regulation of abiotic and biotic stress-related proteins in CCII-expressing potato leaves point to the onset of cystatin-mediated pleiotropic effects in planta altering at some degree the host plant stress metabolism. In particular, our proteomic data suggest a protein-inducing impact of recombinant CCII in potato leaves triggering the constitutive expression of normally inducible defense proteins, and the beneficial impact of this (still unintended) phenotype on plants challenged with the fungal pathogen B. cinerea.

The exact metabolic events driving the up-regulation of stress-related proteins in CCII-leaves remain unclear at this stage. The constitutive expression of several proteins naturally induced by salicylate or its functional analogue benzathiadiazole suggests a role for the salicylic acid signaling pathway, but a more complex picture involving alternative defense pathways cannot be ruled out. For instance, multicystatins in Solanum species are induced by wounding or jasmonic acid [22] but do not respond to fungal elicitors known to reproduce the inducing effects of salicylic acid [54], in apparent disagreement with the hypothetical up-regulation of PMC in CCII-potato lines via a salicylate inducible route. In a similar way, the actual effects of salicylate inducible defenses against $B$. cinerea remain equivocal, given the contrasting effects observed from one plant to another [55] and the various signaling interactions established between host plants and different strains of the pathogen [56]. The high complexity of host plant-B. cinerea interactions in vivo was further illustrated, recently, by a study reporting the deliberate induction of salicylate inducible responses in Nicotiana benthamiana, as a strategy for the pathogen to avoid harmful effects of jasmonate inducible defenses [57].

From a biochemical viewpoint, the occurrence of jasmonate and salicylate inducible proteins in CCII-leaf cells suggests, at this point, the onset of gene (protein)specific effects for the cystatin, presumably initiated by the inhibition of one or several C1A Cys proteases in the cytosolic compartment. Work is underway to identify such putative protease targets, by a dual in silico/ empirical approach involving bioinformatic inferences from Solanaceae genome databases and formal detection of cystatin:protease complexes using activity-based, functional proteomics strategies. Work is also underway to modulate cystatin:Cys protease interactions and their resulting pleiotropic effects in planta, using cystatin single variants engineered to exhibit either stronger or weaker inhibitory activity against Solanaceae protease targets $[58,59]$. The proteomic data provided here should represent, to this end, a useful tool for the efficient, onestep monitoring of multiple stress-related protein alterations in plants expressing the recombinant inhibitors.

\section{Methods}

\section{CCII-expressing potato lines}

Transgenic potato lines expressing CCII were selected from a collection of independent transformants derived from Solanum tuberosum plantlets, cv. Kennebec (see ref. [21] for details on transgene construct). Line K used as parental line for genetic transformation was selected as a control for comparative purposes [9]. The plantlets were acclimated and grown in greenhouse under a 16h:8h light-day photoperiod. Leaf samples for biochemical analyses were frozen in liquid nitrogen and stored at $-80^{\circ} \mathrm{C}$ until use.

\section{CCII detection and quantitation}

mRNA transcripts for CCII in transgenic potato lines were isolated from the $4^{\text {th }}$ leaf of $30-\mathrm{cm}$ plants and assayed by real-time RT PCR as previously described [21], using the following sense and antisense oligonucleotide primers: 5'-GGACGACCTTCACCTCCAGGAGCTC-3' and 5'-GTACATCGTGCCAGCAACCACTTGTG-3'. CCII was immunodetected in soluble protein extracts of the $4^{\text {th }}$ leaf using polyclonal primary antibodies raised in rabbits against oryzacystatin [21]. Relative CCII levels in leaf extracts were assayed by SELDI TOF MS using the Ciphergen's PBSIIc ProteinChip Reader for sample processing, and the Ciphergen ProteinChip software, v. 3.2.0, for data collection and analysis (Bio-Rad, Mississauga ON, Canada) (see [60] for protocol details). CM10 protein biochips for weak cationic exchange were used for protein capture prior to MS analysis. RT PCR and SELDI assays both involved three biological (plant) replicates to allow for statistical assessments. 


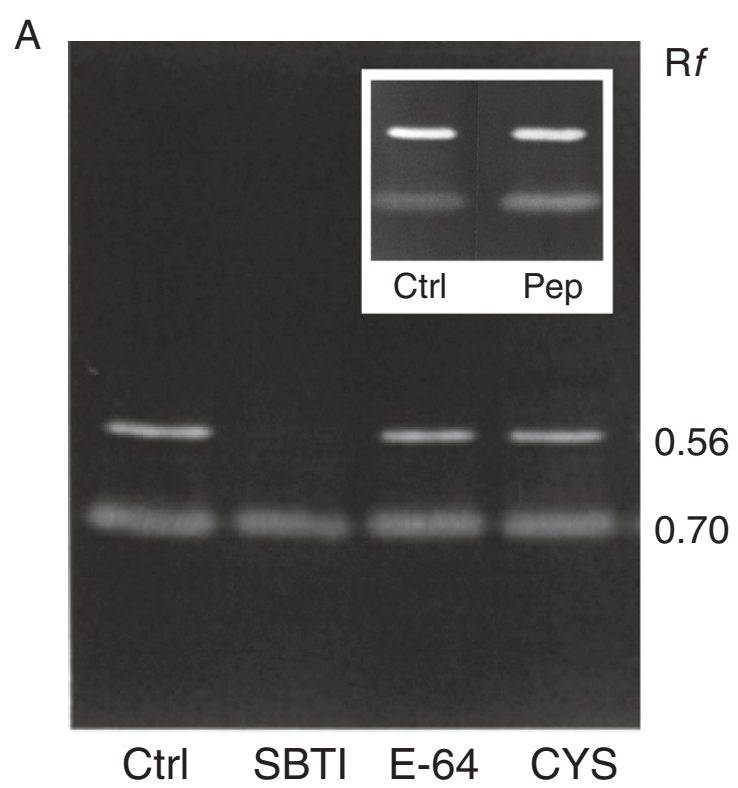

$\mathrm{B}$

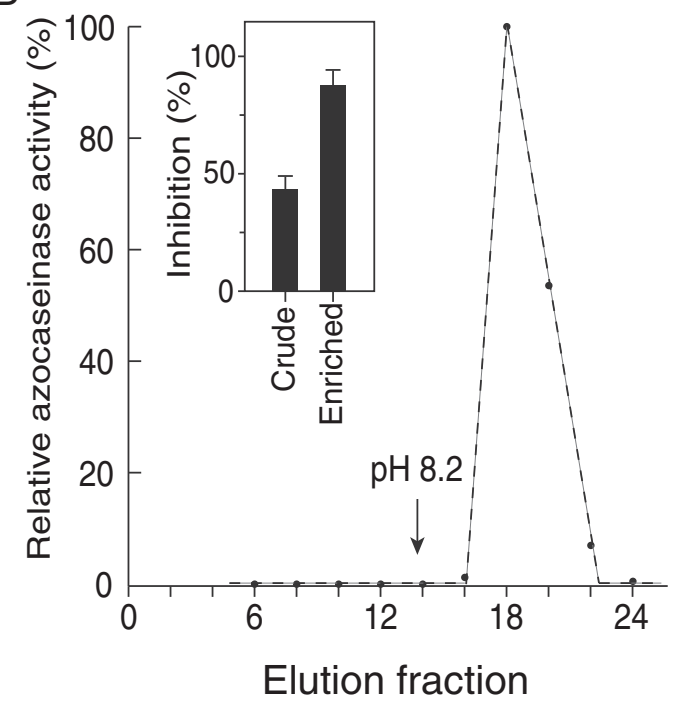

Figure 4 Secreted proteases of the fungal necrotroph Botrytis cinerea. A. Gelatin/SDS-PAGE zymogram showing two protease (gelatinase) bands, pre-incubated or not with class-specific protease inhibitors before electrophoretic separation. Ctrl, control sample, with no inhibitor added; SBTI, soybean trypsin inhibitor; E-64, transepoxysuccinyl-L-leucylamido-(4-guanidino) butane; CYS, oryzacystatin. Rf values on the right refer to relative mobilities in the gel, compared to the protein stain front (arbitrary value of 1.00). B. Elution pattern of $B$. cinerea secreted Asp proteases affinitypurified with pepstatin-agarose beads. The protein extract was passed through a 3-ml pepstatin A-agarose column, and the bound proteases eluted by $\mathrm{pH}$ increase at 8.2. The elution fractions were monitored for azocaseinase activity and sensitivity to pepstatin inhibition (see text for details). The relative inhibitory effects of pepstatin on crude (non-purified) and pepstatin-enriched samples are shown in the inset graph. Data are expressed as relative inhibitory activities compared to a non-inhibited control $(0 \%$ inhibition). Each bar is the mean of three independent values $\pm \mathrm{SE}$.

\section{Expression of defense-related proteins}

mRNA transcripts for the stress protein markers Pin-II and protein $\mathrm{P} 4$ were isolated from the $4^{\text {th }}$ leaf of $30-\mathrm{cm}$ plants and assayed by real-time RT PCR as described [21], using the following sense and antisense DNA primers: 5'-GCGAAGGCTTGCACTTTAGAATGTG-3' and 5'-GGACAAGTCTAGGGTCACATTGCAGGGTAC-3' for Pin-II; and 5'-CTCACTTGTCTCATGGTATTAGCC-3' and 5'-CAGGATCATAGTTGCATGAAATG-3' for protein P4. PR-2 proteins (ß-glucanases) and PR-3 proteins (chitinases) were immunodetected as previously described [21], using polyclonal primary antibodies raised in rabbits against tobacco PR-2 or PR-3 proteins (AgriSera, Vännäs, Sweden). Densitometric analysis of the PR protein signals was performed with the Phoretix 2D Expression software, v. 2005 (NonLinear USA, Durham NC, USA), after scanning the immunoblots with an Amersham Image Scanner digitalizer (GE Healthcare, Baie d'Urfé QC, Canada). PCR and immunodetection assays involved three or four independent (biological) replicates to allow for statistical assessments.

\section{Protein extraction for 2-DE}

Proteins for 2-DE were extracted from the $4^{\text {th }}$ leaf of $30-\mathrm{cm}$ plants. Leaf tissues were ground in liquid nitrogen, and the proteins precipitated at $-20^{\circ} \mathrm{C}$ for $12 \mathrm{~h}$ in $10 \%(\mathrm{v} / \mathrm{v})$ trichloroacetic acid diluted in acetone. Insoluble material was recovered by centrifugation at $4^{\circ} \mathrm{C}$ for $25 \mathrm{~min}$ at 16,000 $\mathrm{g}$, and Speed-Vac centrifugation for 5 min at $20^{\circ} \mathrm{C}$. The proteins were resolubilized in an electrophoretic sample buffer consisting of $8 \mathrm{M}$ urea (Sigma-Aldrich, Oakville ON, Canada) with 2\% (w/v) CHAPS, 0.5\% (v/v) IPG buffer 3-10 (GE Healthcare) and $9.3 \mathrm{mg} \mathrm{ml}^{-1}$ dithiothreitol (Sigma-Aldrich). Protein concentrations were assayed according to Bradford [61], with bovine serum albumin as a standard.

\section{2-DE}

Isoelectric focusing (IEF) for 2-DE was performed along a 3 to 10 non-linear $\mathrm{pH}$ gradient in $13-\mathrm{cm}$ Immobiline DryStrip gel strips (GE Healthcare), with $200 \mu \mathrm{g}$ of leaf protein diluted in $250 \mu \mathrm{l}$ of electrophoretic sample buffer (see above). Proteins were applied to the strips and resolved using an IPGphor system (GE Healthcare). The running program for IEF involved the following steps: rehydration for $12 \mathrm{~h}$ at $30 \mathrm{~V} ; 100 \mathrm{~V}$ for $1 \mathrm{~h} ; 500 \mathrm{~V}$ for $1 \mathrm{~h} ; 1,000 \mathrm{~V}$ for $1 \mathrm{~h} ; 5,000 \mathrm{~V}$ for $1 \mathrm{~h}$; and $8,000 \mathrm{~V}$ to reach $19,000 \mathrm{Vh}$. After IEF, the strips were incubated for $15 \mathrm{~min}$ in $50 \mathrm{mM}$ Tris- $\mathrm{HCl}$ equilibration buffer, $\mathrm{pH} 8.8$, containing $6 \mathrm{M}$ urea, 30\% (v/v) glycerol, 2\% (w/v) SDS and $10 \mathrm{mg} \mathrm{ml}^{-1}$ dithiothreitol, and used immediately for the second dimension. Standard 12\% (w/v) SDS-PAGE [62] was performed in $1 \mathrm{~mm}$-thick polyacrylamide slab gels. After migration, the gels were fixed overnight in 


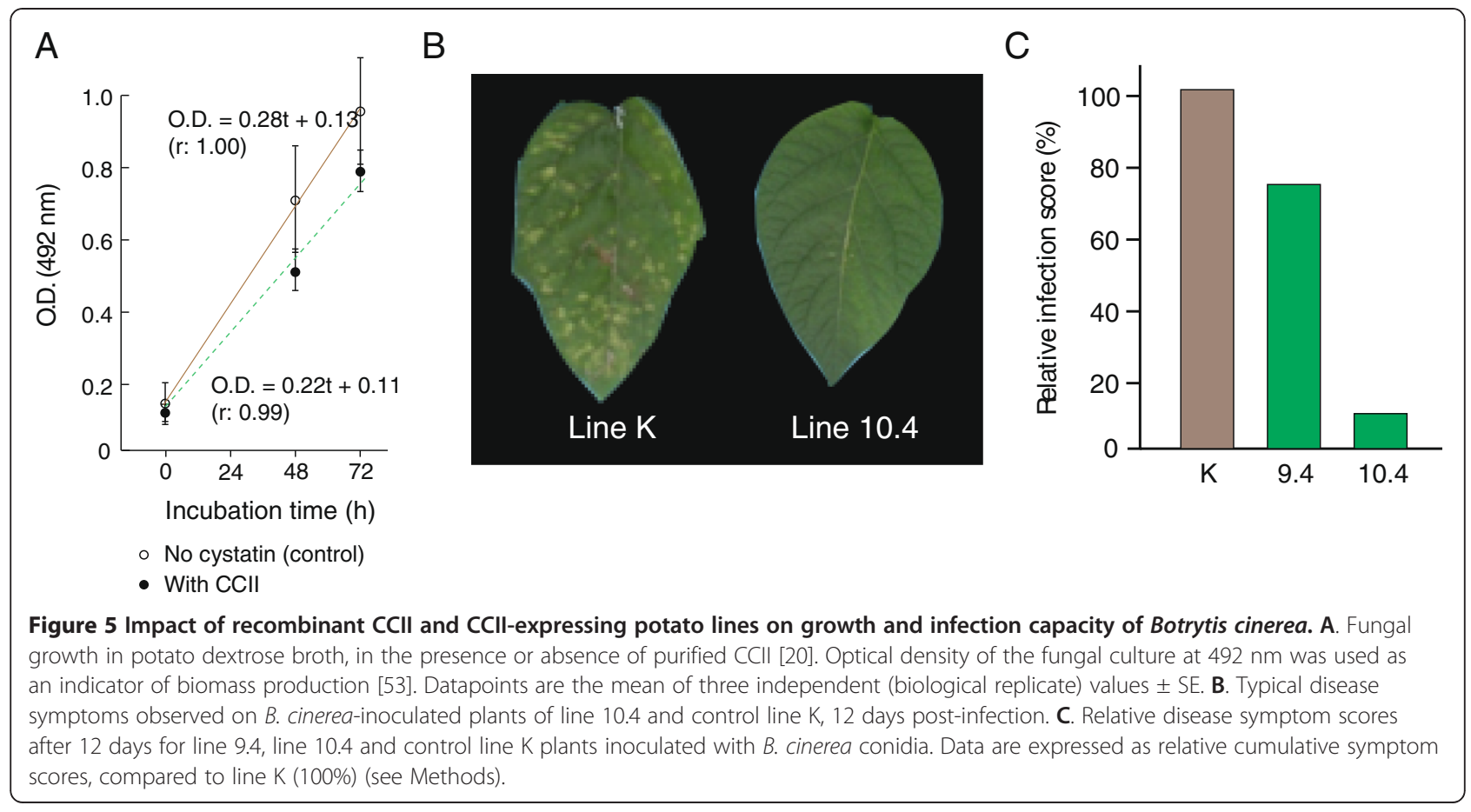

water containing $10 \%(\mathrm{v} / \mathrm{v})$ acetic acid and 40\% (v/v) methanol, and then washed three times in water. Proteins were stained with the GelCode reagent (Pierce, Rockford IL, USA), and the gels scanned using an Amersham Image Scanner digitalizer prior to computer processing.

\section{Image analysis and protein identification}

Image analysis of the 2-D gels was carried out using the Phoretix 2D Expression software, v. 2005 [10], with three biological (plant) replicates for each treatment to allow for statistical analyses (ANOVA; $\alpha=0.05, q=0.05$ ). Protein spots selected for identification were manually excised from the gels, and subject to trypsin automated in-gel digestion in a MassPrep Workstation (Micromass, Manchester UK) [63]. LC-MS/MS analysis was performed at the Génome Québec Centre of McGill University (Montréal QC, Canada), using a Q-TOF micro apparatus (Waters, Milford MA, USA) and a nanosource modified with a nanospray adapter (New Objective, Woburn MA, USA) to hold a PicoFrit column (BioBasic C18 packing, $5 \mu \mathrm{m}, 300 \AA$ ). Peptide sequence data were searched against the NCBInr and NCBI Viridiplantae EST databases, using the Mascot algorithm for protein identification (http://www.matrixscience.com) (Matrix Science, London, UK). Search parameters for protein matching were as follows: one trypsin miscleavage allowed, peptide mass tolerance of $0.3 \mathrm{Da}$, carbamidomethylated Cys residues (fixed modification) and Met residues in oxidized form (variable modification). Protein identifications were accepted when matching scores were significant at $\alpha=0.05$, based on the MOWSE score (Matrix Science).

\section{Botrytis cinerea extracellular proteases}

Extracellular proteases of B. cinerea, isolate 8-8170, were recovered from the liquid phase of a $250-\mathrm{ml}$ culture grown in potato dextrose broth (Difco, Burlington ON, Canada). The fungus was allowed to grow for two weeks in the dark at $20^{\circ} \mathrm{C}$. Fungal mycelium was discarded by filtration through a $0.2 \mu \mathrm{m}$ filter, and the extracellular proteins concentrated by ammonium sulfate precipitation at $90 \%(\mathrm{w} / \mathrm{v})$ saturation. The mixture was centrifuged for $20 \mathrm{~min}$ at $13,000 \mathrm{~g}$, the proteins resuspended in $100 \mathrm{mM}$ citrate phosphate, $\mathrm{pH}$ 6.0, and the resulting solution desalted by gel filtration in a Sephadex G-25 column (GE Healthcare) using the same buffer. Total protease (azocaseinase) activity was measured in mild reducing conditions at $\mathrm{pH}$ 6.0, in the presence or absence of class-specific protease inhibitors (see [64]). The proteases were also resolved by gelatin/SDSPAGE in non-reducing conditions, after pre-incubating the extracts for $15 \mathrm{~min}$ with class-specific inhibitors [65]. An Asp protease not detected in gelatin-containing gels was enriched by pepstatin A affinity chromatography, using pepstatin-agarose beads (Sigma-Aldrich) preequilibrated with $100 \mathrm{mM}$ citrate acetate, $\mathrm{pH}$ 5.0, containing $1 \mathrm{M} \mathrm{NaCl}$ [66]. The samples were passed through a 3-ml agarose column, washed with several volumes of pre-equilibration buffer, and eluted in basic conditions with $100 \mathrm{mM}$ Tris-HCl, $\mathrm{pH}$ 8.2. Fifty- $\mu$ l fractions were collected in eppendorf tubes containing $50 \mu \mathrm{l}$ of $100 \mathrm{mM}$ 
sodium acetate buffer, $\mathrm{pH}$ 3.5, and used as source material for azocaseinase assays (see above).

\section{Impact of recombinant CCII on Botrytis cinerea growth}

The impact of CCII on growth of B. cinerea was assessed by monitoring the optical density of fungal liquid cultures containing a bacterially produced form of the inhibitor [20] at $10 \mu \mathrm{M}$ final concentration. The fungus was allowed to grow in the dark at $20^{\circ} \mathrm{C}$ in potato dextrose broth (Difco). The optical density at $492 \mathrm{~nm}$, indicative of fungal biomass production in vitro [53], was recorded 0,48 and $72 \mathrm{~h}$ after culture initiation, and compared with the corresponding density of a control culture grown in the absence of CCII. Three biological replicates were used for the assay to allow for mean comparisons (Student's $t$-test; $\alpha=0.05$ ).

\section{Impact of CCII-expressing potato lines on Botrytis cinerea infection}

The impact of CCII expression on host plant's resistance to $B$. cinerea was assessed by comparing the incidence and severity of necrotic areas on leaves of control and CCII-expressing lines infected with conidial suspensions of the pathogen. A solid plate culture of the fungus established on potato dextrose agar (Difco) was incubated for three days at $17^{\circ} \mathrm{C}$, under a 12 -h UV light daily regime to induce sporulation. The conidia were washed for $10 \mathrm{~min}$ in $10 \mathrm{ml}$ of water containing $0.05 \%(\mathrm{v} / \mathrm{v})$ Tween 80, counted with a hemocytometer, and their concentration adjusted to $4 \times 10^{5}$ conidia $\mathrm{ml}^{-1}$. The leaves of seven weeks-old control and CCII-expressing plants were wounded with a scrub sponge to weaken the cuticle, and infected with $30 \mu \mathrm{l}$-droplets of the conidial suspension. Relative humidity in the greenhouse was raised to $90 \%$ for $72 \mathrm{~h}$, and then reduced to $70 \%$ for 12 days, before recording disease incidence. Visual symptoms were classified along a ' 0 to 5 ' scale, with a score of 0 indicating the absence of disease symptom. A score of 1 was characterized by the presence of black spots on the vascular tissues; a score of 2 by the presence of chlorosis and necrotic areas; a score of 3 by necrotic lesions covering up to $30-50 \%$ of the leaf surface; a score of 4 by necrotic lesions covering more than $50 \%$ of the leaf surface; and a score of 5 by the evidence of mycelium growth. Four plant replicates were used for each line, with seven leaves (i.e. leaf 3 to leaf 9 , from the apex) inoculated and monitored on each plant to avoid potential confounding effects of leaf age-dependent transgene expression in potato leaves (see [67]). Statistical comparisons of mean values were performed following a logarithmic transformation of the raw data (ANOVA; $\alpha=0.05$ ). Cumulative symptom scores were calculated for each plant line replicate, and the mean cumulative score for each transgenic line compared to the mean cumulative score of control line K (100\%).

\section{Additional file}

Additional file 1: LC-MS/MS identification of leaf proteins up- or downregulated in CCIl-expressing potato lines 9.4 and 10.4 .

\section{Abbreviations}

2-DE: Two-dimensional gel electrophoresis; CCll: Corn cystatin II;

Asp: Aspartate; Cys: Cysteine; E-64: trans-epoxysuccinyl-L-leucylamido-(4guanidino) butane; IEF: Isoelectric focusing; PMC: Potato multicystatin; PR-2 (or PR-3) proteins: Pathogenesis-related proteins 2 (or 3); RT PCR: Reverse transcriptase PCR; SELDI TOF MS: Surface-enhanced laser desorption ionization time-of-flight mass spectrometry; Ser: Serine.

\section{Competing interests}

The authors declare that they have no competing interests.

\section{Authors' contributions}

AM contributed to the experimental design, performed the experiments, and wrote a first draft of the manuscript. KC, LC and LPV contributed to the experiments and to data analysis. CG, RT, MCG and FS contributed to the experimental design and writing of the manuscript. DM conceived the study, contributed to the experimental design, coordinated the experiments, and prepared the last version of the manuscript. All authors read and approved the final manuscript

\section{Acknowledgements}

We thank Ms. Élizabeth Jobin-Michaud for help with the fungal assays. Botrytis cinerea, isolate 8-8170, was kindly provided by Québec government's Laboratoire de diagnostic en phytoprotection (Ministry of Agriculture, Québec City QC, Canada). This work was supported by an operating grant from the Natural Science and Engineering Research Council (NSERC) of Canada, and by a team research grant from the Fonds Québécois de la Recherche sur la Nature et les Technologies. C. Goulet was the recipient of an NSERC graduate scholarship.

\section{Author details}

${ }^{1}$ Centre de recherche en horticulture, Département de phytologie, Université Laval, Pavillon des Services, 2440 boul. Hochelaga, Québec, QC, G1V OA6, Canada. ${ }^{2}$ Current address: Horticulture Sciences Department, University of Florida, Gainesville, FL 32611, USA.

Received: 4 July 2012 Accepted: 29 October 2012

Published: 1 November 2012

\section{References}

1. Haq SK, Atif SM, Khan RH: Protein proteinase inhibitor genes in combat against insects, pests, and pathogens: natural and engineered phytoprotection. Arch Biochem Biophys 2004, 431:145-159.

2. Schlüter U, Benchabane M, Munger A, Kiggundu A, Vorster J, Goulet M-C, Cloutier C, Michaud D: Recombinant protease inhibitors for herbivore pest control: a multitrophic perspective. J Exp Bot 2010, 61:4169-4183.

3. Arai $\mathrm{S}$, Matsumoto I, Emori Y, Abe K: Plant seed cystatins and their target enzymes of endogenous and exogenous origin. J Agric Food Chem 2002, 50:6612-6617.

4. Benchabane M, Schlüter U, Vorster J, Goulet M-C, Michaud D: Plant cystatins. Biochimie 2010, 92:1657-1666.

5. Birk Y: Plant protease inhibitors. New York: Springer; 2003.

6. Schaller A: A cut above the rest: the regulatory function of plant proteases. Planta 2004, 220:183-197.

7. van den Hoorn RAL: Plant proteases: from phenotypes to molecular mechanisms. Annu Rev Plant Biol 2008, 59:191-223.

8. Masoud SA, Johnson LB, White FF, Reeck GR: Expression of a cysteine proteinase inhibitor (oryzacystatin-I) in transgenic tobacco plants. Plant Mol Biol 1993, 21:655-663.

9. Rivard D, Anguenot R, Brunelle F, Le VQ, Vézina L-P, Trépanier S, Michaud D: An in-built proteinase inhibitor system for the protection of 
recombinant proteins recovered from transgenic plants. Plant Biotechnol J 2006, 4:359-368.

10. Badri MA, Rivard D, Coenen K, Michaud D: Unintended molecular interactions in transgenic plants expressing clinically-useful proteins-The case of bovine aprotinin travelling the potato leaf cell secretory pathway. Proteomics 2009, 9:746-756.

11. Goulet C, Benchabane M, Anguenot R, Brunelle F, Khalf M, Michaud D: A companion protease inhibitor for the protection of cytosol-targeted recombinant proteins in plants. Plant Biotechnol J 2010, 8:142-154.

12. Gutiérrez-Campos R, Torres-Acosta JA, Pérez-Martínez JDJ, Gómez-Lim MA: Pleiotropic effects in transgenic tobacco plants expressing oryzacystatin I gene. Hortscience 2001, 36:118-119.

13. Van der Vyver C, Schneidereit J, Driscoll S, Turner J, Kunert K, Foyer CH: Oryzacystatin I expression in transformed tobacco produces a conditional growth phenotype and enhances chilling tolerance. Plant Biotechnol J 2003, 1:101-112.

14. Prins A, van Heerden PDR, Olmos E, Kunert KJ, Foyer CH: Cysteine proteinases regulate chloroplast protein content and composition in tobacco leaves: a model for dynamic interactions with ribulose-1,5bisphosphate carboxylase/oxygenase (Rubisco) vesicular bodies. J Exp Bot 2008, 59:1935-1950.

15. Belenghi B, Acconcia F, Trovato M, Perazzolli M, Bocedi A, Polticelli F, Ascenzi P, Delledonne M: AtCYS1, a cystatin from Arabidopsis thaliana, suppresses hypersensitive cell death. Eur J Biochem 2003, 270:2593-2604.

16. Zhang $X$, Liu S, Takano T: Two cysteine proteinase inhibitors from Arabidopsis thaliana, AtCYSa and AtCYSb, increasing the salt, drought, oxidation and cold tolerance. Plant Mol Biol 2008, 68:131-143.

17. Shan L, Li C, Chan F, Zhao S, Xia G: A Bowman-Birk protease inhibitor is involved in the tolerance to salt stress in wheat. Plant Cell Environ 2008, 31:1128-1137.

18. Srinivasan T, Kumar KRR, Kirti PB: Constitutive expression of a trypsin protease inhibitor confers multiple stress tolerance in transgenic tobacco. Plant Cell Physiol 2009, 50:541-553.

19. Abe M, Abe K, Domoto C, Arai S: Two distinct species of corn cystatin in corn kernels. Biosci Biotechnol Biochem 1995, 59:756-758.

20. Brunelle F, Girard C, Cloutier C, Michaud D: A hybrid, broad-spectrum inhibitor of Colorado potato beetle aspartate and cysteine proteinases. Arch Insect Biochem Physiol 2005, 60:20-31.

21. Badri MA, Rivard D, Coenen K, Vaillancourt L-P, Goulet C, Michaud D: A SELDI-TOF MS procedure for the detection, quantitation, and preliminary characterization of low-molecular-weight recombinant proteins expressed in transgenic plants. Proteomics 2009, 9:233-241.

22. Bouchard É, Cloutier C, Michaud D: Oryzacystatin I expressed in transgenic potato induces digestive compensation in an insect natural predator via its herbivorous prey feeding on the plant. Mol Ecol 2003, 12:2439-2446

23. Rivard D, Cloutier C, Michaud D: Colorado potato beetles show differential digestive compensatory responses to host plants expressing distinct sets of defense proteins. Arch Insect Biochem Physiol 2004, 55:114-123.

24. Tang L, Kwon S-Y, Kim S-H, Kim J-S, Choi JS, Cho KY, Sung CK, Kwak S-S, Lee H-S: Enhanced tolerance of transgenic potato plants expressing both superoxide dismutase and ascorbate peroxidase in chloroplasts against oxidative stress and high temperature. Plant Cell Rep 2006, 25:1380-1386.

25. Tang L, Kim MD, Yang K-S, Kwon S-Y, Kim S-H, Kim J-S, Yun D-J, Kwak S-S, Lee $\mathrm{H}$-S: Enhanced tolerance of transgenic potato plants overexpressing nucleoside diphosphate kinase 2 against multiple environmental stresses. Transgenic Res 2008, 17:705-715.

26. Ahmad R, Kim Y-H, Kim M-D, Kwon W-Y, Cho K, Lee H-S, Kwak S-S: Simultaneous expression of choline oxidase, superoxide dismutase and ascorbate peroxidase in potato plant chloroplasts provides synergistically enhanced protection against various abiotic stresses. Physiol Plant 2010, 138:520-533.

27. Kim MD, Kim Y-H, Kwon W-Y, Yun D-J, Kwak S-S, Lee H-S: Enhanced tolerance to methyl viologen-induced oxidative stress and high temperature in transgenic potato plants overexpressing the CUZnSOD, APX and NDPK2 genes. Physiol Plant 2010, 140:153-162.

28. Kim Y-H, Kim MD, Choi Yl, Park S-C, Yun D-J, Noh EW, Lee H-S, Kwak S-S: Transgenic poplar expressing Arabidopsis NDPK2 enhances growth as well as oxidative stress tolerance. Plant Biotechnol J 2011, 9:334-347.
29. Dmitriev A, Tena M, Jorrin J: Systemic acquired resistance in sunflower (Heliothus annuus L.). Tsitol Genet 2003, 37:9-15.

30. Malolepsza U: Induction of disease resistance by acibenzolar-S-methyl and o-hydroxyethylorutin against Botrytis cinerea in tomato plants. Crop Protect 2010, 25:956-962.

31. Zhang JY, Qiao YS, Ly D, Gao ZH, Qu SC, Zhang A: Malus hupehensis NPR1 induces pathogenesis-related protein gene expression in transgenic tobacco. Plant Biol Supp/ 2012, 1:46-56.

32. Vellicce GR, Diaz Ricci JC, Hernandez L, Castagnaro AP: Enhanced resistance to Botrytis cinerea mediated by the transgenic expression of the chitinase gene ch5B in strawberry. Transgenic Res 2006, 15:57-68.

33. Distefano G, La Malfa S, Vitale A, Lorito M, Deng Z, Gentile A: Defence-related gene expression in transgenic lemon plants producing an antimicrobial Trichoderma harzianum endochitinase during fungal infection. Transgenic Res 2008, 17:873-879.

34. Khan RS, Ntui VO, Chin DP, Nakamura I, Mii M: Production of marker-free disease-resistant potato using isopentenyl transferase gene as a positive selection marker. Plant Cell Rep 2011, 30:587-597.

35. Gilroy EM, Hein I, van der Hoorn R, Boevink PC, Venter E, McLellan H, Kaffarnik F, Hrubikova K, Shaw J, Holeva M, Lopez EC, Borras-Hidalgo O, Pritchard L, Loake GJ, Lacomme C, Birch PRJ: Involvement of cathepsin B in the plant disease resistance hypersensitive response. Plant J 2007, 52:1-13.

36. Rojo E, Martin R, Carter C, Zouhar J, Pan S, Plotnikova J, Jin H, Paneque M, Sanchez-Serrano JJ, Baker B, Ausubel FM, Raikhel NV: VPEg exhibits a caspase-like activity that contributes to defense against pathogens. Curr Biol 2004, 14:1897-1906.

37. Govrin EM, Levine A: The hypersensitive response facilitates plant infection by the necrotrophic pathogen Botrytis cinerea. Curr Biol 2000 10:751-757.

38. Govrin EM, Rachmilevith S, Tiwari BS, Solomon M, Levine A: An elicitor from Botrytis cinerea induces the hypersensitive response in Arabidopsis thaliana and other plants and promotes the gray mold disease. Phytopathology 2006, 96:299-307.

39. Imani J, Baltruschat H, Stein E, Jia G, Vogelsberg J, Kogel K-H, Hückelhoven R: Expression of barley BAX Inhibitor- 1 in carrots confers resistance to Botrytis cinerea. Mol Plant Pathol 2006, 7:279-284.

40. van Baarlen P, Woltering EJ, Staats M, van Kan JAL: Histochemical and genetic analysis of host and non-host interactions of Arabidopsis with three Botrytis species: an important role for cell death control. Mol Plant Pathol 2007, 8:41-54.

41. Rossi FR, Garriz A, Marina M, Romero FM, Gonzalez ME, Gonzalez Collado I, Pieckenstain FL: The sesquiterpene botrydial produced by Botrytis cinerea induces the hypersensitive response on plant tissues and its action is modulated by salicylic acid and jasmonic acid signaling. Mol Plant Microbe Interact 2011, 24:888-896.

42. Shah P, Atwood JA III, Orlando R, El Mubarek H, Podila GK, Davis MR: Comparative proteomic analysis of Botrytis cinerea secretome. J Proteome Res 2009, 8:1123-1130.

43. Fernandez-Acero FJ, Colby T, Harzen A, Carbu M, Wieneke U, Cantoral JM, Schmidt J: 2-DE proteomic approach to the Botrytis cinerea secretome induced with different carbon sources and plant-based elicitors. Proteomics 2010, 10:2270-2280.

44. Movahedi S, Heale JB: The roles of aspartic protease and endo-pectin lyase enzymes in the primary stages of infection and pathogenesis of various host tissues by different isolates of Botrytis cinerea Pesr. ex Pers. Physiol Mol Plant Pathol 1990, 36:303-324.

45. ten Have A, Dekkers E, Kay J, Phylip LH, van Kan JAL: An aspartic proteinase gene family in the filamentous fungus Botrytis cinerea contains members with novel features. Microbiology 2004, 150:2475-2489.

46. Rolland S, Bruel C, Rascle C, Girard V, Billon-Grand G, Poussereau N: pH controls both transcription and post-translational processing of the protease BCACP1 in the phytopathogenic fungus Botrytis cinerea. Microbiology 2009, 155:2097-2105.

47. Michaud D: Gel electrophoresis of proteolytic enzymes. Anal Chim Acta 1998, 372:173-185

48. Yang $\mathrm{AH}$, Yeh $\mathrm{KW}$ : Molecular cloning, recombinant gene expression, and antifungal activity of cystatin from taro (Colocasia esculenta cv. Kaosiung no. 1). Planta 2005, 221:493-501. 
49. Christova PK, Christov NK, Imai R: A cold inducible multidomain cystatin from winter wheat inhibits growth of the snow mold fungus, Microdochium nivale. Planta 2006, 223:1207-1218.

50. Carrillo L, Herrero I, Cambra I, Sanchez-Monge R, Diaz I, Martinez M: Differential in vitro and in vivo effect of barley cysteine and serine protease inhibitors on phytopathogenic microorganisms. Plant Physiol Biochem 2011, 49:1191-1200.

51. Martinez M, Lopez-Solanilla E, Rodriguez-Palenzuela P, Carbonero P, Diaz I: Inhibition of plant-pathogenic fungi by the barley cystatin Hv-VPI (gene Icy) is not associated with its cysteine-proteinase inhibitory properties. Mol Plant Microbe Interact 2003, 16:876-883.

52. Martinez M, Abraham Z, Gambardella M, Echaide M, Carbonero P, Diaz l: The strawberry gene Cyf1 encodes a phytocystatin with antifungal properties. J Exp Bot 2005, 56:1821-1829.

53. Broekaert WF, Terras FRG, Cammue BPA, Vanderleyden J: An automated quantitative assay for fungal growth inhibition. FEMS Microbiol Lett 1990, 69:55-60.

54. Girard C, Rivard D, Kiggundu A, Kunert K, Gleddie SC, Cloutier C, Michaud D: A multicomponent, elicitor-inducible cystatin complex in tomato, Solanum lycopersicum. New Phytol 2007, 173:841-851.

55. Rowe HC, Walley JW, Corwin J, Chan EK-F, Dehesh K, Kliebenstein DJ: Deficiencies in jasmonate-mediated plant defense reveal quantitative variation in Botrytis cinerea pathogenesis. PLoS Path 2010, 6(4):e1000861.

56. Achuo EA, Audenaert K, Meziane H, Höfte M: The salicylic acid-dependent defence pathway is effective against different pathogens in tomato and tobacco. Plant Pathol 2004, 53:65-72.

57. El Oirdi M, El Rahman TA, Rigano L, El Hadrami A, Rodriguez MC, Daayf F, Vojnov A, Bouarab K: Botrytis cinerea manipulates the antagonistic effects between immune pathways to promote disease development in tomato. Plant Cell 2011, 23:2405-2421.

58. Kiggundu A, Goulet M-C, Goulet C, Dubuc J-F, Rivard D, Benchabane M, Pépin G, van der Vyver C, Kunert K, Michaud D: Modulating the proteinase inhibitory profile of a plant cystatin by single mutations at positively selected amino acid sites. Plant J 2006, 48:403-413.

59. Goulet M-C, Dallaire C, Vaillancourt L-P, Khalf M, Badri MA, Preradov A Duceppe M-O, Goulet C, Cloutier C, Michaud D: Tailoring the specificity of a plant cystatin toward herbivorous insect digestive cysteine proteases by single mutations at positively selected amino acid sites. Plant Physiol 2008, 146:1010-1019.

60. Badri MA, Coenen K, Vaillancourt L-P, Goulet C, Michaud D: On-chip detection of low-molecular-weight recombinant proteins in plant crude extracts by SELDI-TOF MS. Meth Mol Biol 2009, 483:313-324.

61. Bradford MM: A rapid and sensitive method for the quantitation of microgram quantities of protein utilizing the principle of protein-dye binding. Anal Biochem 1976, 72:248-254.

62. Laemmli UK: Cleavage of structural proteins during the assembly of the head of bacteriophage T4. Nature 1970, 227:680-685.

63. Wasiak S, Legendre-Guillemin V, Puertollano R, Blondeau F, Girard M de Heuvel E, Boismenu D, Bell AW, Bonifacino JS, McPherson PS Enthoprotin: a novel clathrin-associated protein identified through subcellular proteomics. J Cell Biol 2002, 158:855-862.

64. Michaud D, Nguyen-Quoc B, Yelle S: Selective inhibition of Colorado potato beetle cathepsin H by oryzacystatins I and II. FEBS Lett 1993, 331:173-176.

65. Michaud D, Cantin L, Raworth DA, Vrain TC: Assessing the stability of cystatin/cysteine proteinase complexes using mildly-denaturing gelatinpolyacrylamide gel electrophoresis. Electrophoresis 1996, 17:74-79.

66. Morrisson CJ, Hurst SF, Bragg SL, Kuykendall RJ, Diaz H, McLaughlin DW Reiss E: Purification and characterization of the extracellular aspartyl proteinase of Candida albicans: removal of extraneous proteins and cell wall mannoprotein and evidence for lack of glycosylation. J Gen Microbiol 1993, 139:1177-1186.

67. Cloutier C, Jean C, Fournier M, Yelle S, Michaud D: Adult Colorado potato beetles, Leptinotarsa decemlineata compensate for nutritional stress on oryzacystatin I transgenic potato plants by hypertrophic behavior and over-production of insensitive proteases. Arch Insect Biochem Physiol 2000, 44:69-81.

doi:10.1186/1471-2229-12-198

Cite this article as: Munger et al.: Beneficial 'unintended effects' of a cereal cystatin in transgenic lines of potato, Solanum tuberosum. BMC Plant Biology 2012 12:198.

\section{Submit your next manuscript to BioMed Central and take full advantage of:}

- Convenient online submission

- Thorough peer review

- No space constraints or color figure charges

- Immediate publication on acceptance

- Inclusion in PubMed, CAS, Scopus and Google Scholar

- Research which is freely available for redistribution

Submit your manuscript at www.biomedcentral.com/submit
C Biomed Central 